\section{Cureus}

Received 06/05/2018

Review began 06/11/2018

Review ended 07/20/2018

Published 07/23/2018

\section{C) Copyright 2018}

Khoury et al. This is an open access article distributed under the terms of the Creative Commons Attribution License CC-BY 3.0., which permits unrestricted use, distribution, and reproduction in any medium, provided the original author and source are credited.

\title{
The Natural History of Hematemesis in the 21st Century
}

Leen Khoury ${ }^{1}$, David A. Hill M.D. ${ }^{2}$, Melissa Panzo ${ }^{3}$, Melissa Chiappetta ${ }^{4}$, Sachin Tekade ${ }^{4}$, Stephen M. Cohn ${ }^{5}$

1. Research/surgery, Staten Island University Hospital/Northwell Health, Staten Island, USA 2. Plastic and Reconstructive Surgery, Houston Methodist Hospital, Houston, USA 3. Research, Staten Island University Hospital/Northwell Health, New York, USA 4. Surgery, Staten Island University Hospital/Northwell Health, Staten Island, USA 5. Surgery, Staten Island University Hospital, Queens Village, USA

$\square$ Corresponding author: Leen Khoury, lkhoury@northwell.edu Disclosures can be found in Additional Information at the end of the article

\section{Abstract}

Objective: Upper gastrointestinal (GI) bleeding occurs at a rate of 40-150 episodes per 100,000 persons per year and is associated with a mortality rate of $6 \%-10 \%$. We sought to determine the need for therapeutic endoscopy or surgical interventions in patients with hematemesis and the association with blood transfusion requirements.

Methods: We queried the database of our large teaching facility for adult patients presenting with obvious upper GI hemorrhage (hematemesis) between 2014 and 2017. We evaluated the amount of blood transfusions administered and the need for operative, endoscopic or angiographic interventions.

Results: Eighty-one patients were admitted with hematemesis: mean age was 63 years old (range 21-103), 60\% were male, and mean hemoglobin was $11.3 \mathrm{~g} / \mathrm{dL}$ (range 3.6-15.6). Fortyone percent received blood transfusions with a mean of one unit transfused per patient (range $0-10$ ); $9 \%$ received $\geqslant 3$ units of packed red blood cells. Bleeding stopped spontaneously in $88 \%$ of patients and nine died. Forty-seven percent underwent inpatient endoscopy but only 6\% underwent a therapeutic endoscopic intervention. No patient had a surgical or interventional radiologic procedure related to their GI bleed.

Conclusion: Upper GI bleeding rarely requires operative or interventional radiologic intervention. Blood transfusions were not predictive of the need for therapeutic endoscopic intervention which was required in only $6 \%$ of patients.

Categories: General Surgery

Keywords: gastrointestinal bleeding, upper gastrointestinal hemorrhage, hematemesis, therapeutic endoscopy

\section{Introduction}

Gastrointestinal (GI) hemorrhage results in approximately 300,000 hospital admissions in the United States annually. Upper GI bleeds occur at a rate of 40-150 episodes per 100,000 persons per year, with a mortality rate of $6 \%-10 \%$ [1].

With the advent of new anti-ulcer medications, the diseases associated with upper GI bleeding 
are now better controlled and the resulting complications associated with these illnesses appears to be in a state of decline. In the United States, the incidence rates for hospital discharges with the diagnosis of peptic ulcer disease decreased from 1,400 per 100,000 people in 1979 to approximately 700 per 100,000 in 2004 [2]. Upper GI bleeding decreased from 78.4 to 60.6 per 100,000 people between 2001 and 2009 and there has been a decrease in peptic ulcer bleeding from 48.7 to 32.1 per 100,000 [3].

With all of these changes regarding diseases associated with upper GI bleeding, we sought to determine the need for therapeutic endoscopy or surgery in patients with hematemesis and the association with blood transfusion. We hypothesized that the need for therapeutic interventions in patients presenting with hematemesis has decreased dramatically.

\section{Materials And Methods}

A retrospective chart review was performed which examined adult patients admitted to Staten Island University Hospital, a 714 bed teaching facility, with a diagnosis of upper gastrointestinal (GI) bleeding between 2014 and 2017. During that time, 318 patients were admitted to the hospital with a diagnosis of upper GI bleeding. Of these patients, eighty-one were included in our study as they presented with hematemesis (vomiting of bloody gastric fluid or had blood on nasogastric aspiration).

The endpoints of the study were: endoscopic, operative, or angiographic interventions performed and total blood transfusions administered. Therapeutic management (surgical, interventional radiology, endoscopic), transfusion requirements, mortality and length of hospital stay as well as basic demographic information were analyzed. We also studied the relationship between the amount of blood transfused and the types of interventions performed.

The Institutional Review Board of Northwell Health/Feinstein Institute provided protocol approval and a waiver of informed consent was obtained. Statistical analysis was performed utilizing student t-test to evaluate continuous variables. Non-continuous variables were evaluated using a Chi square analysis. Statistical significance was set at a value of $\mathrm{p}<0.05$.

\section{Results}

Eighty-one patients were admitted with obvious upper GI bleeding (hematemesis). The mean age was 63 years old (range 21-103) with 60\% being male. Average admission hemoglobin was 11.3 (range 3.6-15.6 g/dl) (Table 1). 


\section{Cureus}

\begin{tabular}{|c|c|c|c|c|c|}
\hline & & Total & $\begin{array}{l}\text { Endoscopic } \\
\text { Intervention }\end{array}$ & $\begin{array}{l}\text { No Endoscopic } \\
\text { Intervention }\end{array}$ & $\begin{array}{l}\text { P- } \\
\text { Values }\end{array}$ \\
\hline Total & & 81 & 5 & 76 & \\
\hline Male Sex & & $61 \%$ & $40 \%$ & $62 \%$ & 0.333 \\
\hline Anticoagulation Medication Use & & $38 \%$ & $60 \%$ & $37 \%$ & 0.302 \\
\hline Antiplatelet Medication Use & & $10 \%$ & $0 \%$ & $11 \%$ & 0.445 \\
\hline $\begin{array}{l}\text { Combination of Antiplatelet and } \\
\text { Antithrombotic Medication }\end{array}$ & & $5 \%$ & $0 \%$ & $5 \%$ & 0.599 \\
\hline $\begin{array}{l}\text { Anticoagulant or Antiplatelet Medication } \\
\text { Reversal Agent Administered }\end{array}$ & & $9 \%$ & $0 \%$ & $9 \%$ & 0.478 \\
\hline$\geq 3$ units PRBC Transfused & & $7 \%$ & $0 \%$ & $8 \%$ & 0.514 \\
\hline Systolic BP (mmHg) & Mean & $\begin{array}{l}125(72- \\
221)\end{array}$ & $145(107-221)$ & $123(72-193)$ & 0.073 \\
\hline HR (beats/minute) & Mean & $\begin{array}{l}87.7 \\
(52-155)\end{array}$ & $107.2(90-155)$ & $86.4(52-128)$ & 0.008 \\
\hline Admission Hgb (g/dl) & Mean & $\begin{array}{l}11.3(6- \\
17.5)\end{array}$ & $9.1(7.1-11.4)$ & $11.4(6-17.5)$ & 0.079 \\
\hline Lowest Hgb (g/dl) & Mean & $\begin{array}{l}9.4 \\
(3.6- \\
15.6)\end{array}$ & $8(6.3-9.6)$ & $9.5(3.6-15.6)$ & 0.182 \\
\hline Transfusion Required & & $41 \%$ & $60 \%$ & $40 \%$ & 0.366 \\
\hline Amount transfused (units of PRBC) & Median & $0(0-10)$ & $1(0-2)$ & $0(0-10)$ & 0.922 \\
\hline
\end{tabular}

\section{TABLE 1: Patient demographics}

BP: blood pressure; HR: heart rate; Hgb: hemoglobin; PRBC: packed red blood cells; IR: interventional radiology; GI: gastrointestinal; N/A:not applicable.

In $38 \%$ of cases, patients were on antiplatelet or anticoagulation medications, (5\% on both). Reversal agents were used in $18 \%$ of patients taking either of these types of medications.

Bleeding stopped spontaneously in $88 \%$ of patients without any intervention. Eleven percent of patients $(n=9)$ died. Deaths were related to refusal of transfusions, requests for comfort care measures, withdrawal of care or other causes unrelated to GI bleeding. Three of these deaths were due directly to GI bleeding. One expiration was a patient with multiple medical comorbidities (hypertension, venous thrombosis and atrial fibrillation) on warfarin with an International Normalized Ratio (INR) of eight. This patient also had an active do not resuscitate and do not intubate order. Despite intravenous fluids, fresh frozen plasma, blood transfusion and vasopressors the patient rapidly deteriorated and expired. The second patient died as a result of massive hemorrhage from a gastric ulcer. The patient was initially admitted 


\section{Cureus}

with a diagnosis GI bleeding, but left the hospital against medical advice. Three days later the patient returned to the hospital with continued upper GI bleeding, deteriorated, developed cardiogenic shock and was unable to be resuscitated. The third expiration was a patient whom the family requested comfort care measures only. After a month-long stay, the patient died on the day of discharge to hospice care.

Forty-seven percent of patients underwent inpatient endoscopy, but only $6 \%$ received a therapeutic endoscopic intervention (Figure 1).

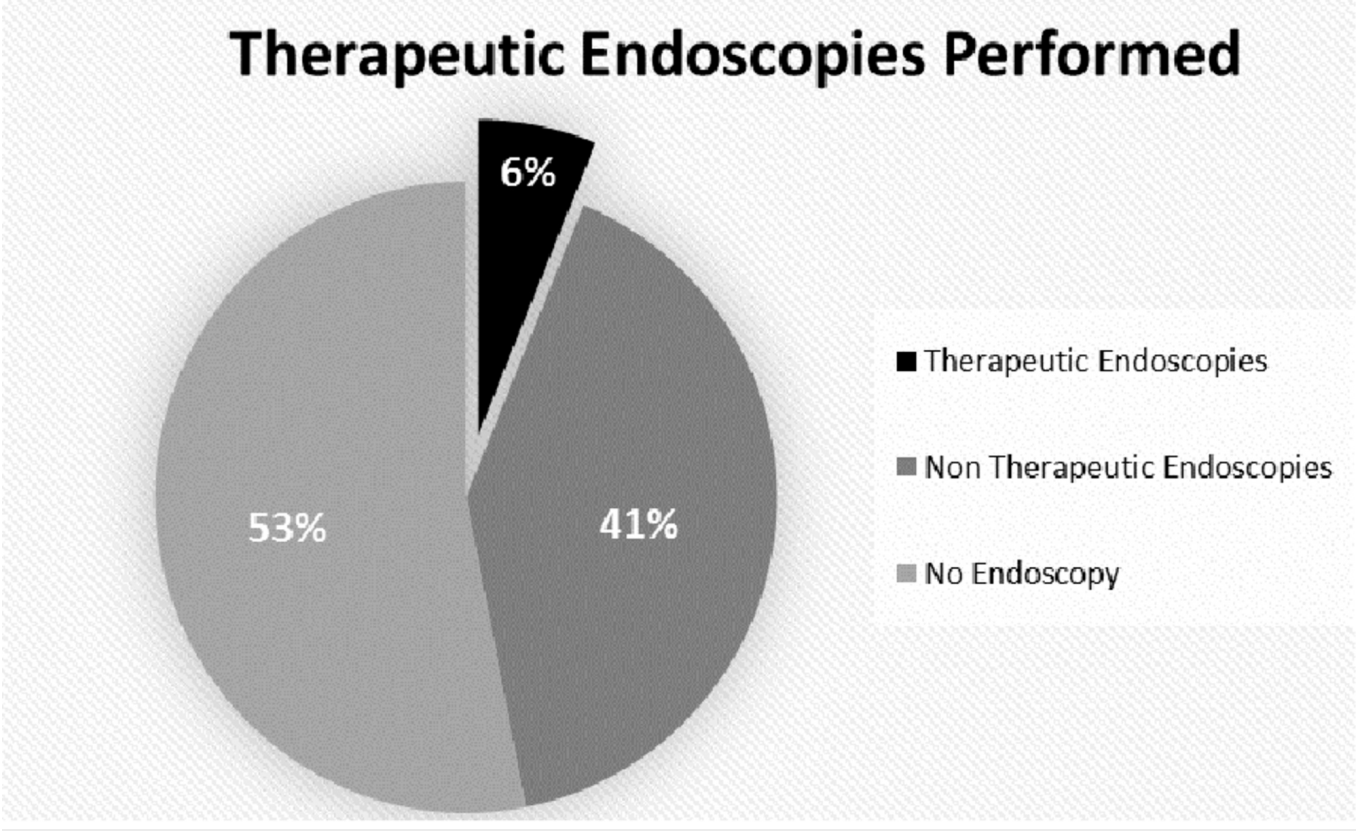

FIGURE 1: Endoscopies performed

Sixty percent of patients undergoing therapeutic endoscopy were on anti-platelet or anticoagulation medications. The average admission hemoglobin was $9.12 \mathrm{~g} / \mathrm{dl}$ for those receiving a therapeutic endoscopy versus $11.43 \mathrm{~g} / \mathrm{dl}$ in patients not undergoing an endoscopic intervention ( $\mathrm{p}=0.078$ ). Mean blood transfusion required for patients undergoing endoscopic intervention was one unit, but was 0 units in those not undergoing an intervention. No patients receiving $\geqslant 3$ units of blood underwent a therapeutic intervention. No statistically significant differences in mortality, length of hospital stay or transfusion requirements were noted when those patients receiving a therapeutic endoscopy where compared with those who did not. No patients received a surgical or interventional radiologic procedure related to their GI bleed (Table 2). 


\section{Cureus}

\begin{tabular}{|c|c|c|c|c|c|}
\hline & & Total & Endoscopic Intervention & No Endoscopic Intervention & P-Values \\
\hline \multicolumn{2}{|l|}{ Total } & 81 & 5 & 76 & \\
\hline \multicolumn{2}{|c|}{ Surgery Performed for GI Bleeding } & $0 \%$ & $0 \%$ & $0 \%$ & N/A \\
\hline \multicolumn{2}{|c|}{ IR Procedure Performed } & $0 \%$ & $0 \%$ & $0 \%$ & N/A \\
\hline \multicolumn{2}{|l|}{ Died } & $11 \%(9)$ & $0 \%(0)$ & $12 \%(9)$ & 0.414 \\
\hline Length of stay (days) & Median & $3(0-27)$ & $2(1-8)$ & $3(0-27)$ & 0.702 \\
\hline
\end{tabular}

\section{TABLE 2: Endoscopic interventions versus no endoscopic interventions}

IR: interventional radiology; GI: gastrointestinal; N/A:not applicable.

Only one patient underwent surgery, a craniotomy for evacuation of subdural hematoma. This patient presented to the hospital unresponsive and made no neurologic progress after their operation. The family withdrew care and the patient expired the next day.

In regards to blood transfusions: $41 \%$ had blood transfusions with a mean of one unit transfused per patient (range 0 to 10). Nine percent of patients received three or more units of packed red blood cells (PRBCs) and 7\% received three or more units in the first 24 hours after admission. None of these patients requiring $>3$ units of blood had a therapeutic endoscopic, surgical or interventional radiologic procedure (Table 3). 


\section{Cureus}

\begin{tabular}{|c|c|c|c|c|c|}
\hline & & Total & $\begin{array}{l}\geq 3 \text { units PRBC (first } 24 \\
\text { hrs) }\end{array}$ & $\begin{array}{l}<3 \text { units PRBC (first } \\
24 \mathrm{hrs)}\end{array}$ & $\begin{array}{l}\text { P- } \\
\text { Value }\end{array}$ \\
\hline \multicolumn{2}{|l|}{ Total } & 81 & 6 & 75 & \\
\hline \multicolumn{2}{|l|}{ Male Sex } & $61 \%$ & $67 \%$ & $60 \%$ & 0.748 \\
\hline Systolic BP (mmHg) & Mean & $\begin{array}{l}125(72- \\
221)\end{array}$ & $105(98-112)$ & $126(72-221)$ & 0.054 \\
\hline Admission Hgb (g/dl) & Mean & $\begin{array}{l}11.3(6- \\
17.5)\end{array}$ & $8.6(6.3-10.5)$ & $11.5(6-17.5)$ & 0.014 \\
\hline Lowest Hgb (g/dl) & Mean & $\begin{array}{l}9.4(3.6- \\
15.6)\end{array}$ & $6.9(6-8)$ & $9.6(3.6-15.6)$ & 0.008 \\
\hline \multicolumn{2}{|l|}{ Transfusion Required } & $40.7 \%$ & $100 \%$ & $36 \%$ & 0.002 \\
\hline \multicolumn{2}{|c|}{$\begin{array}{l}\text { On Antiplatelet or Anticoaguant } \\
\text { Medication }\end{array}$} & $44 \%$ & $50 \%$ & $44 \%$ & 0.776 \\
\hline \multicolumn{2}{|l|}{ Endoscopy Performed } & $6 \%$ & $67 \%$ & $45 \%$ & 0.314 \\
\hline \multicolumn{2}{|c|}{ Therapeutic Endoscopy Performed } & $6 \%$ & $0 \%$ & $7 \%$ & 0.514 \\
\hline \multicolumn{2}{|c|}{ Surgery Pertormed for Gl Bleeding } & $0 \%$ & $0 \%$ & $0 \%$ & - \\
\hline \multicolumn{2}{|c|}{ IR Procedure Performed } & $0 \%$ & $0 \%$ & $0 \%$ & - \\
\hline \multicolumn{2}{|c|}{$\begin{array}{l}\text { Any Therapeutic Intervention } \\
\text { Performed }\end{array}$} & $49 \%$ & $0 \%$ & $9 \%$ & 0.434 \\
\hline \multicolumn{2}{|l|}{ Died } & $2.5 \%$ & $0 \%$ & $12 \%$ & 0.368 \\
\hline Length of stay (days) & Median & $3(0-2 /)$ & $7.5(3-14)$ & $3(0-27)$ & 0.121 \\
\hline
\end{tabular}

TABLE 3: Comparison of $>3$ units of PRBC transfused versus $<3$ units of PRBC transfused

BP: blood pressure; HR: heart rate; Hgb: hemoglobin; PRBC: packed red blood cells; IR: interventional radiology; GI: gastrointestinal.

\section{Discussion}

GI bleeding continues to be an important medical issue causing approximately 67 per 100,000 hospitalizations annually in the US [4]. The average hospitalization costs are estimated to be between $\$ 3,402$ to $\$ 5,632$ for nonvariceal upper GI bleeding, and $\$ 6,612$ to $\$ 23,207$ for variceal related bleeding [5]. Fortunately, the hospitalization rates for the diagnosis of upper GI hemorrhage decreased by $21 \%$ from 2002 to 2012 . The diagnosis of gastritis and peptic ulcer disease had the largest decrease in GI bleed related incidence, 55\% and 30\% respectively [4]. Perhaps this is in part due to the implementation of new medical therapies such as proton pump inhibitors or treatment of Helicobacter pylori [6]. Mortality rates have also improved by $28 \%$ [4]. This is likely due to improvements in resuscitation and advances in therapeutic 
endoscopic techniques [6]. The need for therapeutic interventions, however, appears to be diminishing. In our study, $47 \%$ of the patient population received an endoscopy but only $6 \%$ required a therapeutic endoscopic intervention. In $88 \%$ of patients, the bleeding stopped spontaneously.

In addition, we found no association between patients receiving more than three units of PRBCs and the need for intervention. These patients who required significant transfusions typically presented with lower hemoglobin values and received more transfusions. However, no patients who received more than three units of PRBCs required any therapeutic procedures, including surgical, interventional radiological or endoscopic.

This study is limited by a small population, despite a three-year review at a large urban hospital. We had limited information about endoscopies occurring immediately prior to admission or after discharge. Also, we had limited data on the timing from bleeding to endoscopy, but nearly $90 \%$ of bleeding stopped spontaneously.

\section{Conclusions}

The need for surgical, interventional radiologic or therapeutic endoscopy is rarely required in the treatment of patients presenting with obvious upper GI bleeding. In $88 \%$ of patients with hematemesis, bleeding resolves spontaneously. There is no association between transfusion requirements and the need for a therapeutic intervention.

\section{Additional Information}

\section{Disclosures}

Human subjects: Consent was obtained by all participants in this study. Northwell Health Institutional Review Board issued approval 16-944. To: Stephen M Cohn, MD 475 SEAVIEW AVENUE STATEN ISLAND, NY 10305 From: Hallie Kassan, MS, CIP Director, Human Research Protection Program Date: February 01, 2017 RE: IRB \#: 16-944 Protocol Title: Etiology of Lower Gastrointestinal Bleeding in the 21st Century, Has it Changed? Approval Date: February 01, 2017 Expiration Date: January 31, 2018 Dear Dr. Cohn The above referenced project meets the criteria outlined in 45 CFR 46.110 and 21 CFR 56.110 for EXPEDITED REVIEW and has been approved. The following category(ies) apply(ies) to the project: 45 CFR 46.110 (5): Research involving materials (data, documents, records, or specimens) that have been collected, or will be collected solely for nonresearch purposes (such as medical treatment or diagnosis) Expedited Approval of this project includes: 1. Application for Chart Review xform submitted to the IRB on: $1 / 4 / 20162$. This study has been issued a waiver of informed consent and HIPAA authorization. 3. The following study personnel are authorized to participate in the study: Stephen Cohn, Leen Khoury, Melissa Panzo, David Hill, Miroslav Kopp. The study cannot begin until you receive institutional approval. The Institutional Review Board will be notified of this action at its meeting. This study has not been approved for the inclusion of pregnant women, children, or prisoners. If you would like to include these populations, please notify the IRB for further instruction. The IRB approval expiration date is listed above. As a courtesy, approximately 60 to 90 days prior to expiration of this approval, the Office of the IRB will send an e-mail reminding you to apply for continuing review. Failure to receive renewal notification does not relieve you of your responsibility to provide the Progress Report to the IRB in time for the request to be processed and approved prior to your expiration date. It is your responsibility to apply for continuing review and receive continuing approval for the duration of the study. Lapses in approval should be avoided to protect the safety and welfare of enrolled subjects. Subject recruitment methods for enrollment are appropriate, there is equitable selection of subjects, and there are provisions to protect and maintain the confidentiality of data and research participants. Investigators are reminded that research must be conducted in 
accordance with all applicable Department of Health and Human Services regulations 45 CFR 46, Food and Drug Administration regulations 21CFR 50, 21CFR 56, 21 CFR 812, and the Health Insurance Portability and Accountability Act (HIPAA). All studies are subject to audits by the Office of Research Compliance and/or Institutional Review Board to confirm adherence to institutional, state, and federal regulations governing research. NOTE: This approval is subject to recall if at any time the conditions and requirements as specified in the IRB Policies and Procedures are not followed (see next page and web site:

http://www.northshorelij.com/body.cfm?ID=2804) NOTE: All IRB Policies and Procedures must be followed, including the following: 1. Using only IRB-approved consent forms, questionnaires, letters, advertisements, etc. in your research. 2. Submitting any modifications made to the study for IRB review prior to the initiation of changes except when necessary, to eliminate apparent, immediate hazards to the subject. 3. Reporting unanticipated problems involving risk to subjects or others. 4. Prior to implementation, any changes made to studies utilizing TAP must have COPP, as well as IRB approval. IMPORTANT REMINDER: The International Committee of Medical Journal Editors (ICMJE) requires registration of clinical research studies meeting specific guidelines prior to publication. Please see ICMJE requirements for registration of clinical trials at http://www.icmje.org. Our organization account is in the name of the North Shore-Long Island Jewish Health System. To register your trial: http://prsinfo.clinicaltrials.gov. You must register your trial PRIOR TO ENROLLING SUBJECTS. . Animal subjects: All authors have confirmed that this study did not involve animal subjects or tissue. Conflicts of interest: In compliance with the ICMJE uniform disclosure form, all authors declare the following: Payment/services info: All authors have declared that no financial support was received from any organization for the submitted work. Financial relationships: All authors have declared that they have no financial relationships at present or within the previous three years with any organizations that might have an interest in the submitted work. Other relationships: All authors have declared that there are no other relationships or activities that could appear to have influenced the submitted work.

\section{References}

1. Kim BS, Li BT, Engel A, et al.: Diagnosis of gastrointestinal bleeding: a practical guide for clinicians. World J Gastrointest Pathophysiol. 2014, 5:467-78. 10.4291/wjgp.v5.i4.467

2. Tielleman T, Bujanda D, Cryer B: Epidemiology and risk factors for upper gastrointestinal bleeding. Gastrointest Endosc Clin N Am. 2015, 25:415-28. 10.1016/j.giec.2015.02.010

3. Laine L, Yang H, Chang SC, Datto C: Trends for incidence of hospitalization and death due to GI complications in the United States from 2001 to 2009. Am J Gastroenterol. 2012, 107:11905. 10.1038/ajg.2012.168

4. Wuerth BA, Rockey DC: Changing epidemiology of upper gastrointestinal hemorrhage in the last decade: a nationwide analysis. Dig Dis Sci. 2018, 63:1286-1293. 10.1007/s10620-0174882-6

5. Adam V, Barkun AN: Estimates of costs of hospital stay for variceal and nonvariceal upper gastrointestinal bleeding in the United States. Value Health. 2008, 11:1-3. 10.1111/j.15244733.2007.00208.x

6. Pérez-Aisa MA, Del Pino D, Siles M, Lanas A: Clinical trends in ulcer diagnosis in a population with high prevalence of Helicobacter pylori infection. Aliment Pharmacol Ther. 2005, 21:6572. 10.1111/j.1365-2036.2004.02297.x 